\title{
Um encontro especial em Cluj-Napoca Georges Banu teatralmente homenageado na sua Roménia natal
}

\author{
Maria Helena Serôdio
}

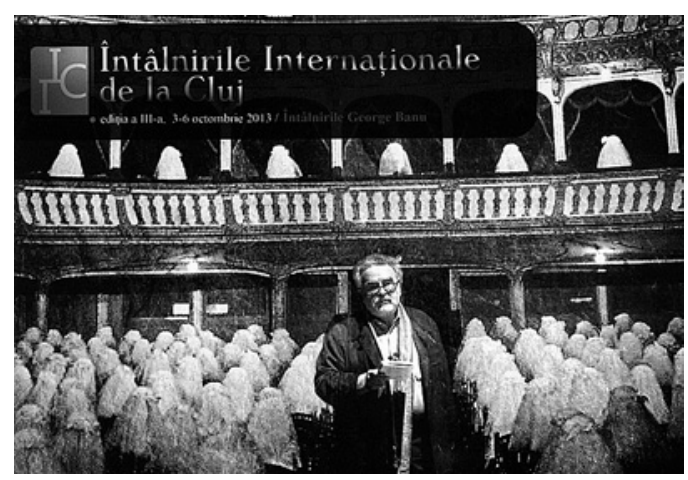

1. Razões e momentos para celebrar Entre os dias 3 e 6 de Outubro de 2013, os Encontros Internacionais em Cluj-Napoca - na sua terceira edição - celebraram Georges Banu, o brilhante investigador, crítico, professor e teórico de teatro, Presidente Honorário da Associação Internacional de Críticos de Teatro, e, não menos decisivo, o compagnon de route de vários importantes fazedores do teatro nosso contemporâneo. Autor de inúmeros livros sobre - e a propósito de - teatro, foi também a vertente da sua reflexão em torno das relações entre a pintura e a cena teatral o que permitiu alargar o âmbito dos debates que decorreram no Teatro Nacional de Cluj-Napoca e que integravam Adam Birö, o editor dos três belíssimos livros em que Banu invoca a convergência produtiva e inspirada das duas artes: Le rideau ou la fêlure du monde (1997), L'homme de dos: Peinture / théâtre (2000) e Nocturnes: Peindre la nuit, jouer dans le noir (2005).

No evento participaram investigadores, críticos e artistas de teatro, mas a iniciativa juntou também - porque a cidade é assim na sua riqueza cultural - os dois teatros que são os pólos vivos e de superior qualidade artística nas artes do palco: o Teatro Nacional de Cluj-Napoca e o Teatro Húngaro de Cluj. 0 Museu de Arte da cidade foi também parceiro da homenagem e convidou Georges Banu para curador de uma exposição especial que celebrasse a "noite" a partir do acervo do Museu. A curadoria juntou Banu e Dominic Stegerean (de um canal cultural da televisão nacional), oferecendo aos visitantes da exposição uma interessantíssima colecção de pinturas que representavam, inventavam e celebravam a noite. A

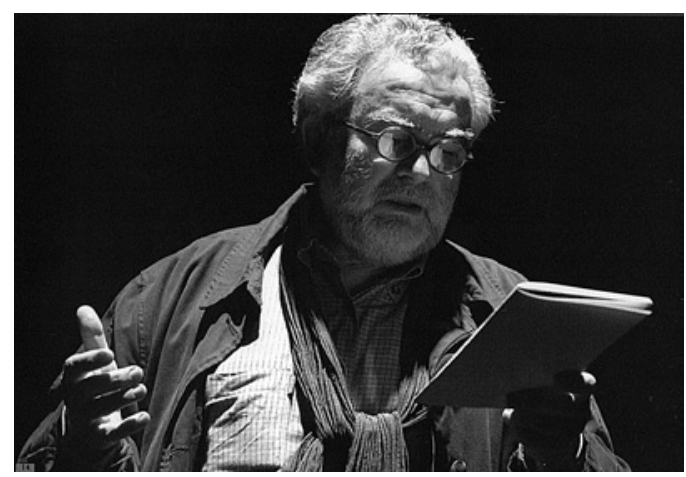

Cartaz dos Encontros Internacionais Cluj-Napoca 2013, dedicados a Georges Banu.

Fotografia de Georges Banu. esse roteiro artístico juntou-se o lançamento, no Teatro Nacional, de mais um livro de Banu traduzido para romeno por Dana Monah e Roxana Monah - Nocturno - e que saiu com a chancela da Editora Nemira. Outros livros de teatro foram lançados no contexto destes encontros: Amor e desamor do teatro, ainda de Georges Banu, agora em versão romena (pelas edições Polirom) e húngara (pela editora Koinonia), já saído antes em francês nas edições Actes Sud; Close to the Stage. George Banu, Essays and Testimonies, um volume, pelas edições Curtea Veche, organizado por Iulian Boldea eŞtefana Pop-Curşeu; publicações várias, como as que registam uma longa entrevista, em edição romena e húngara, a András Visky, o dramaturgo residente do Teatro Húngaro da cidade e director associado da companhia.

Não faltou a convocação de outras artes que permitiram um recital de piano por Georgiana Fodor, da Academia de Música de Cluj-Napoca, no foyer do 2. ${ }^{\circ}$ andar do Teatro Nacional, e um recital pela soprano Hélène Delavault (acompanhada ao piano por Cyrille Lehn), bem como a projecção de dois filmes: Georges Banu: Um retrato (realizado por Sînziana Miloşoiu, numa produção daTVR2) e - por escolha de Georges Banu - o visionamento de uma excepcional realização filmica do Tio Vânia, de Tchekov, realizada por Louis Malle, com o actor André Gregory: Vanya on $42^{\text {nd }}$ Street.

A despedida destes vivissimos Encontros Internacionais incluiu, na noite de 6 de Outubro, no foyer do balcão do Teatro Nacional, uma animada apresentação pelo Grupo de Música Tradicional Iza de Maramures, que inspirou público e artistas a uns bons e animados pés de dança. 


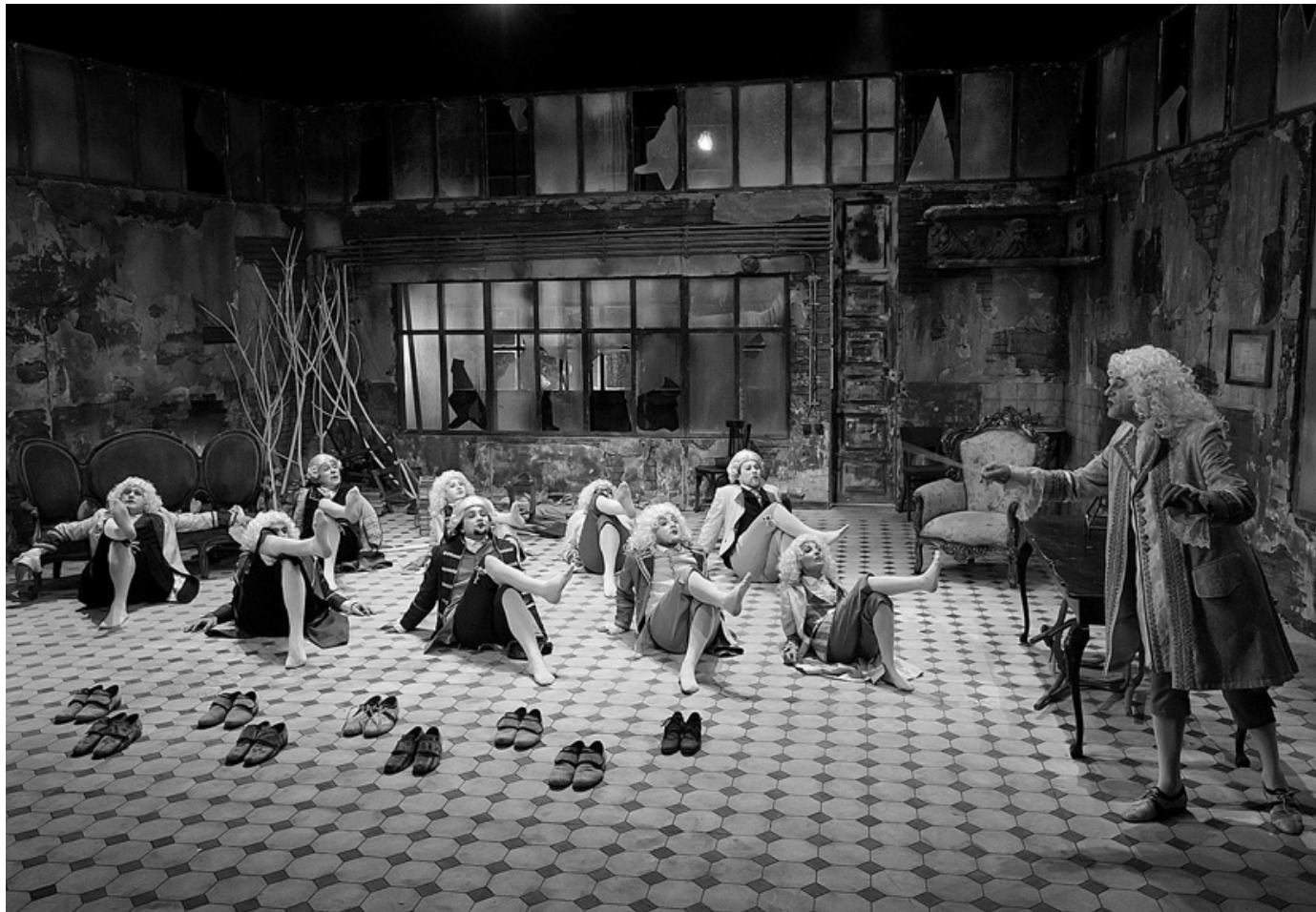

de Georg Büchner,

enc. Gabor Tompa,

Teatrul Maghiar de Stat

Cluj (Teatro Húngaro

de Clui), 2011,

fot. Biró István
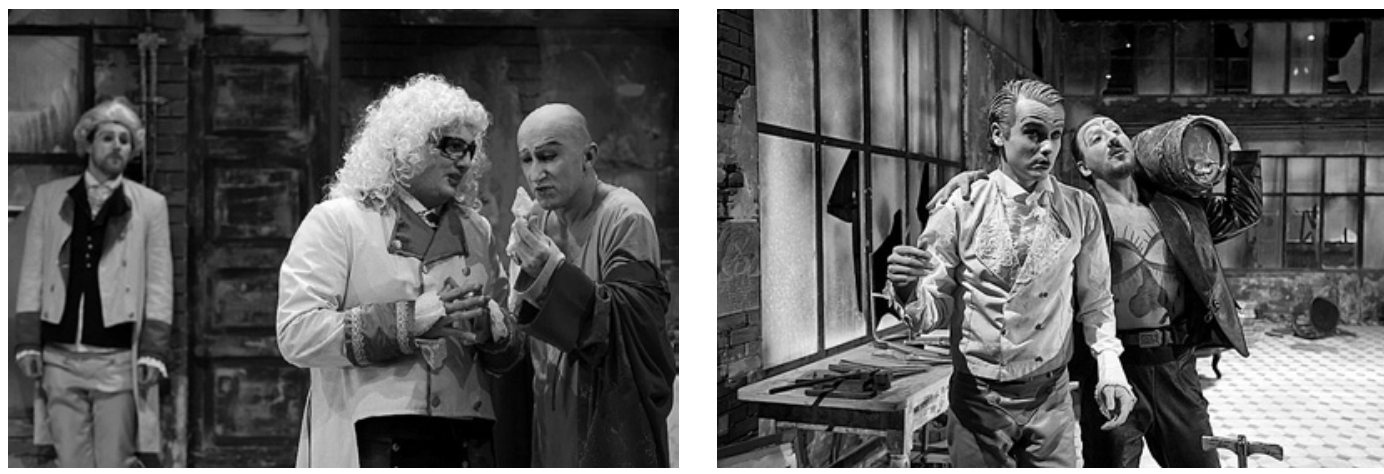

No campo das intervenções e debates registaram-se participações variadas de artistas e estudiosos, como fo o caso de András Visky, Sorin Alexandrescu, Ion Vartic, Anca Măniuţiu, Ion Cocora,Ştefana Pop-Curşeu, Carmen Muşat Monica Andronescu, Iulian Boldea (em torno do tema Espectador e crítico: Da sombra do palco ao testemunho na página), bem como de Laurent Gaudé, Adam Biro, Jean François Dusigne, Maria Helena Serôdio, András Visky, Miha Măniuţiu, Liviu Maliţa, Marina Constantinescu (em torno de Porquê o teatro hoje?).

Para lá do convívio e da verificação do interesse e gosto pelo teatro vivo - na sua prática e nas reflexões que suscita -, os Encontros permitiram assistir a espectáculos de valor verdadeiramente antológico, reforçando a convicção de que a criação teatral na Roménia é um alfobre de prodigiosa invenção artística.

Silviu Purcarete abriu os Encontros com a encenação da peça A Hell of a Mess! (Uma confusão dos diabos!) de Eugène lonesco no grande palco do Teatro Nacional, e o Teatro Húngaro trouxe à sua pequena sala-estúdio a obra de Johannes von Tepl (também conhecido como Johannes von Saaz, c. 1350-c.1415) com o espectáculo O lavrador e a morte escrito em 1411, impresso em 1460 e conhecido também como 0 lavrador da Boémia ${ }^{1}$, sob a direcção

magistral de Mihai Măniuțiu.

Ainda no Teatro Húngaro, na sua sala maior, foi possivel ver duas encenações de Gábor Tompa: Leóncio e Lena, de Büchner, e Nascido para nunca, de András Visky, cuja criação cénica registava um sobressalto elegíaco perturbador.

Duas outras produções do Teatro Nacional se apresentaram nestes Encontros Internacionais: A trilogia Aureliu Manea, encenada também por Gabór Tompa, e, num exercício de criatividade transbordante, Sânziana e Pepelea, a partir da peça desmesurada e cómica de Vasile Alecsandri encenada por Alexandru Dabija.

Esta edição dos Encontros Internacionais apresentavase também como argumento suplementar a acompanhar a candidatura da cidade de Cluj a Capital Cultural Europeia em 2021, como recordava Mihai Măniutiu, o Director Geral do Teatro Nacional de Cluj, no programa do evento que juntou artistas, críticos, teóricos e um público atento e cúmplice.

\section{Em cena no Teatro Nacional}

No palco principal do Teatro Nacional, a peça de lonesco surgia com dois títulos consoante era referida em francês ou em inglês no programa deste festival: era Ce formidable 


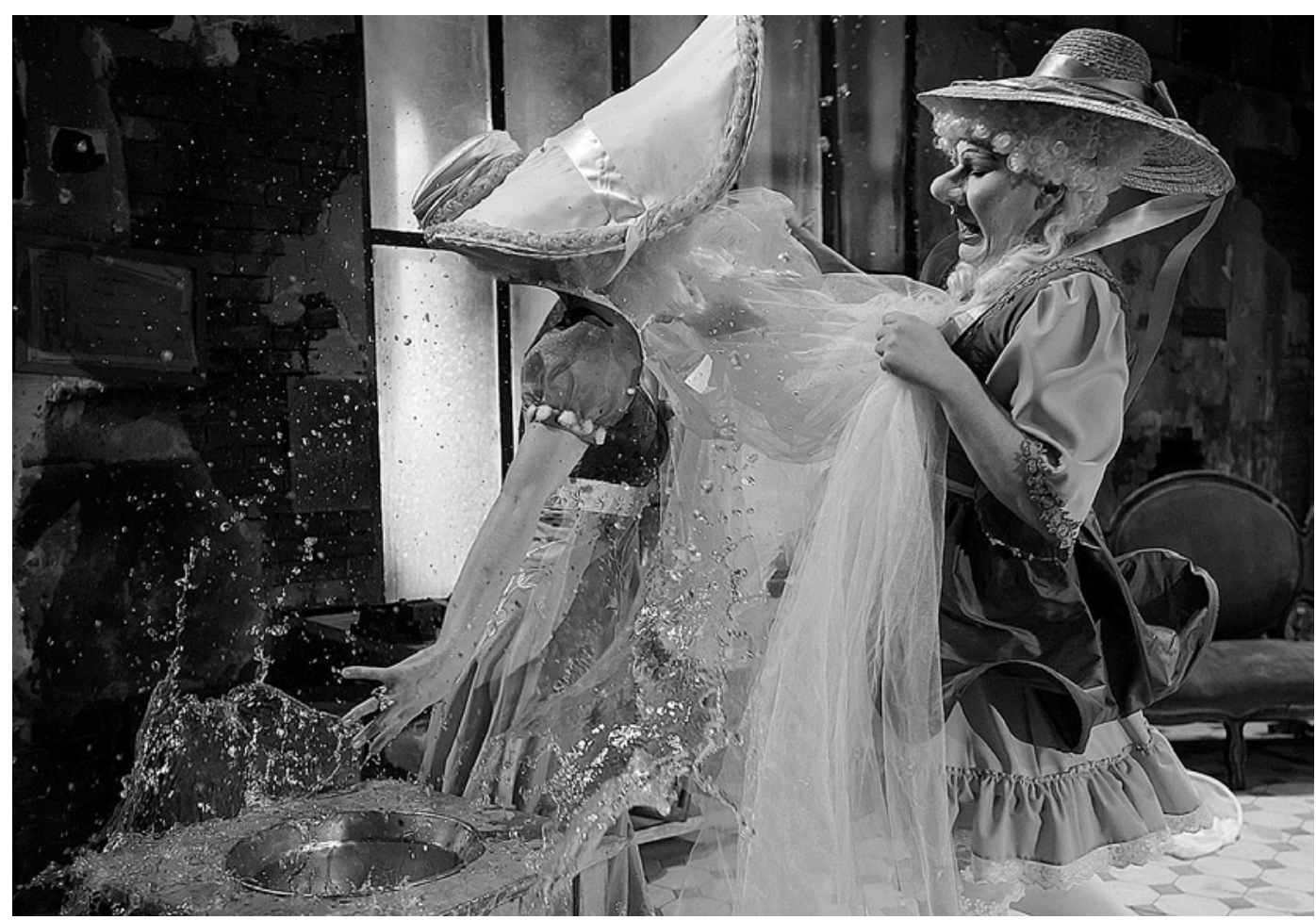

bordel! ("Esse formidável bordel!") em francês e A Hell of a Mess! ("Uma confusão dos diabos!") em inglês. E a verdade é que ambos os títulos se mostravam eloquentes relativamente ao que em cena se mostrava. De facto, uma prodigiosa imagem inicial, em atmosfera de sombras, mostrava uma longa fila de figuras à esquerda no palco e 0 andamento do espectáculo iria mostrar que muitas dessas figuras eram simples manequins, mas que com uma destreza extraordinária acabavam por ser movidos em cena para referir a desinquietação em que mora um casal, bem como as muitas confusões que se criam no quotidiano. Tudo feito e mostrado numa competência explosiva de vivacidade e movimento.

0 cenário convocava mesas de bilhar, um bar, mas também um interior doméstico, juntando situações e palavras de ordem que poderiam remeter para os anos 1960 e 1970 na reivindicação de liberdade na sexualidade, mas também declarações contraditórias de "longa vida à ditadura", ou invocando os gritos opostos contra os ricos e contra os pobres. Seguia-se um breve itinerário de questões que marcaram esse tempo: Che Guevara, tecnologia, economia política...

De resto, o programa citava a declaração do autor relativamente ao que dizia ser a base a partir da qual construia as suas peças: dois estados de espírito que se revelavam fundamentais e que ora surgiam em alternativa, ora se justapunham: "a consciência da evanescência e da solidez, a consciência do vazio e da presença excessiva, a consciência da transparência irreal do mundo e da sua opacidade, a consciência da luz e das trevas espessas".

Ainda nesse mesmo teatro, mas na sala estúdio Eiphorion, estreou o espectáculo A trilogia Aureliu Manea, que incluía as peças Penélope continua pensativa, 0 ensaio de teatro e A fada do Oriente. Nascido em 1945, Aureliu Manea foi colega de faculdade de Andrei Serban e estreouse em 1969 com a encenação de Romersholm, de Ibsen, em Sibiu. Foi também cineasta importante, mas retirou-se no início dos anos 90 por motivos de saúde. Curiosamente, em 2011, foi sobre um texto seu que o realizador Gheorghe Preda filmou Breakdown, uma história sobre o colapso mental de uma enfermeira psiquiátrica. 0 valor da obra de Manea tem vindo, de facto, a ser amplamente reconhecido, e não são poucas as vozes que actualmente lamentam não the ter sido dada a oportunidade de revelar internacionalmente a sua especial criatividade. Na trilogia estreada no Teatro Nacional - dramaturgicamente elaborada por András Visky e com encenação de Gábor Tompa - a morte revelava ser uma presença obsessiva e, embora podendo corresponder a uma intensa sede de amor, não deixava de sinalizar uma relação possessiva entre mãe e filho, criando-se um universo visionário em que a figuração das Parcas se podia associar à atmosfera lorquiana de uma Bernarda Alba na relação - aqui - com o filho. Com uma cenografia inventiva e forte de Carmencita Brojboiu, o espectáculo mereceu uma expressiva ovação por parte do público.

0 terceiro espectáculo apresentado no Teatro Nacional, Sânziana e Pepelea, baseava-se num texto de Vasile Alecsandri de 1881, e, na encenação de Alexandru Dabija, surgia como uma fantasia entre um certo imaginário popular e um divertimento para os mais jovens, apesar de não ser este, de modo algum, o público visado pelo espectáculo. Tinha, todavia, um pouco de ambos, e revelou ser uma complicada trama que usava - e ao mesmo tempo empurrava para - um certo ridículo alguns dos lugares comuns dos contos de fadas "romenos". A cena inicial mostrava pendões religiosos, mulheres vestidas de preto e, no telão ao fundo, projectadas árvores sem folhas compondo um cenário romântico onde não faltava uma torre em ruínas com uma enorme janela gótica.

Aparentemente as beatas seguravam o casulo do padre e pediam chuva para acabar com a praga de gafanhotos que infestava aquela aldeia. Só que o "sacrificio", que um tal milagre comportava, consistia em afogar uma velha, 


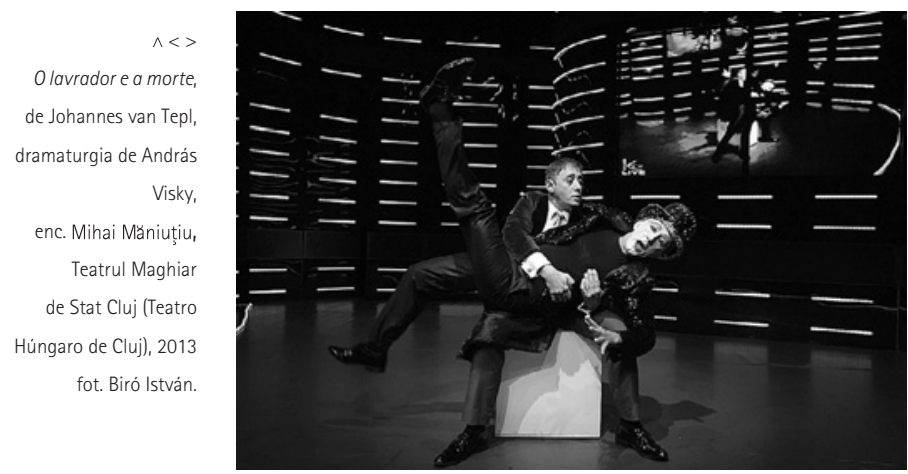

o que foi de imediato cumprido pela povoação em alvoroço. Não faltarão, nesta história longa e complicada, pássaros que falam e raptam princesas, um príncipe encantado, um dragão, muitos instrumentos musicais, que incluem a gaita de foles, trombone e guitarra. Enfim, resumindo, uma complicada e risivel história de "desencantar", mas que se tornou num divertimento teatral para o público que enchia a sala.

\section{Em cena no Teatro Húngaro}

No Teatro Húngaro tivemos a oportunidade de ver três espectáculos muito diferentes, mas todos de uma qualidade insuperável.

O lavrador da Boémia (ou O lavrador e a morte), sobre texto de Johannes von Tepl, teve encenação enérgica e trepidante de Mihai Măniuţiu, lembrando, de algum modo, o célebre filme All That Jazz, de Bob Fosse, pela luzes e cores fortes que vão invadindo um cenário de painéis brilhantes e de iluminação feérica referido a um estúdio televisivo. 0 resumo da acção explicaria o seu ritmo alucinante, numa espécie de imaginário de cabaret que se impôs em cena: $K$, o famoso e enigmático produtor e estrela - de televisão, dono de várias cadeias televisivas, decidiu produzir um programa intitulado "A morte e 0 lavrador" baseado no texto de Johannes von Tepl. A razão próxima deste programa tinha sido a morte inesperada e súbita da sua mulher, e o desenrolar frenético, mas tenso, da representação tem a ver com a incógnita sobre se no final, K. a grande vedeta deste musical se suicidará ou não.

Entretanto, para a representação de Leóncio e Lena, de Georg Büchner - encenada, como já mencionado, por Gábor Tompa - foi escolhida a sala grande do teatro, representando o cenário um lugar passivel de se referir ao séc. XVIII, mas com claros sinais de decadência e abandono. Era uma espécie de grande salão de janelas rasgadas (mas com alguns vidros partidos), que parecia concitar a curiosidade dos que passavam no fundo da
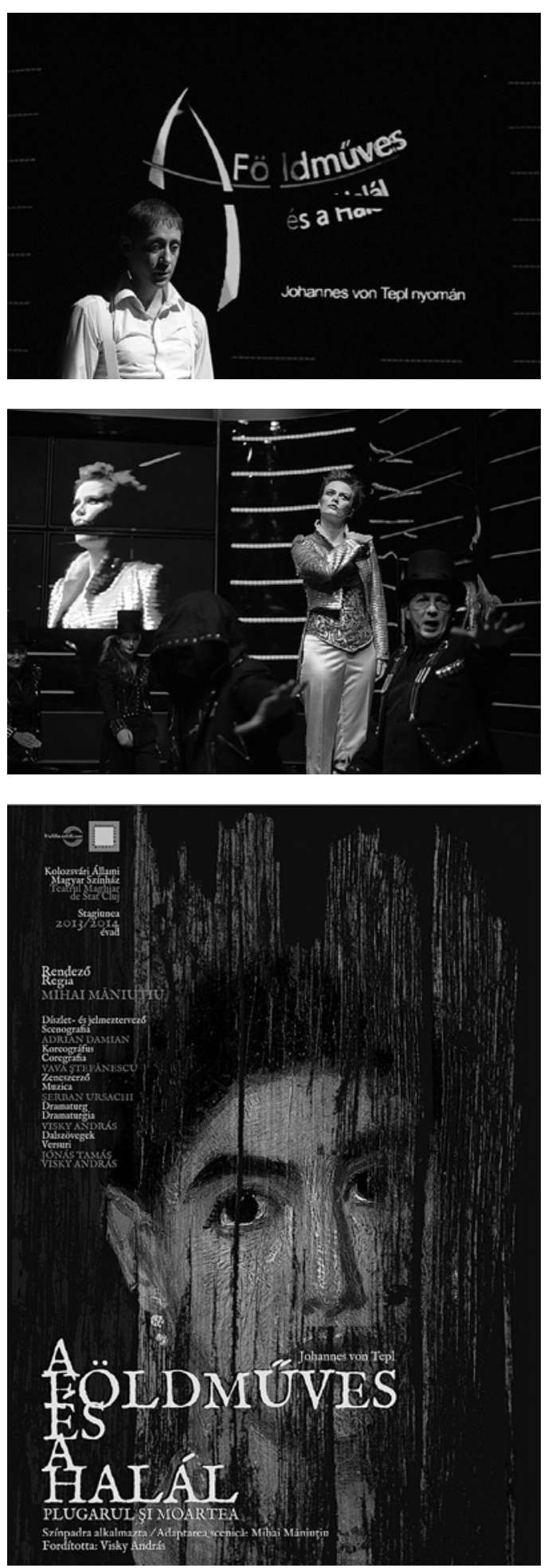

cena. As paredes apresentavam-se sujas e delapidadas, o chão era de ladrilhos de desenho geométrico, e por ali se amontoavam sofás desarticulados, ramos secos de árvores, livros atados em pilhas, e cadeiras tombadas pelo chão. As cabeleiras brancas (e verdes), os rostos empoados e clownescos, os figurinos coloridos, tudo apontava para Setecentos, mas num registo de farsa teatral mais própria de uma trupe de actores ambulantes, do que uma real evocação de época. Como registava o programa do espectáculo, a peça de Büchner terá sido uma das primeiras a apresentar "o mecanismo que despersonaliza e separa 

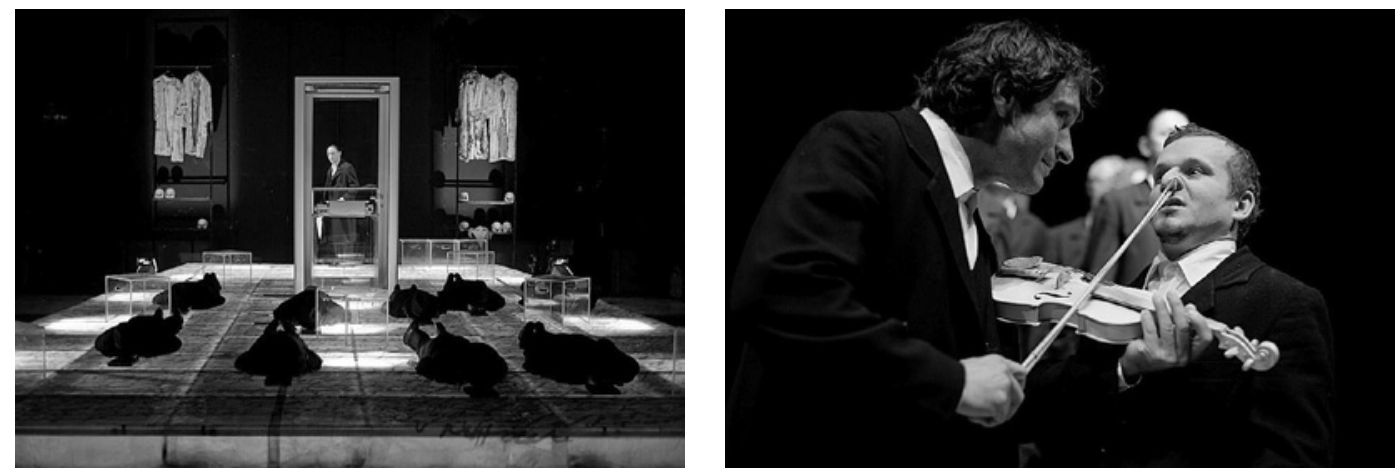

$<><v>v$

Nascido para nunca,

de András Nisky,

enc. Gabór Tompa, Teatrul Maghiar de Stat Cluj (Teatro Húngaro de Cluj), 2009, fot. Biró István
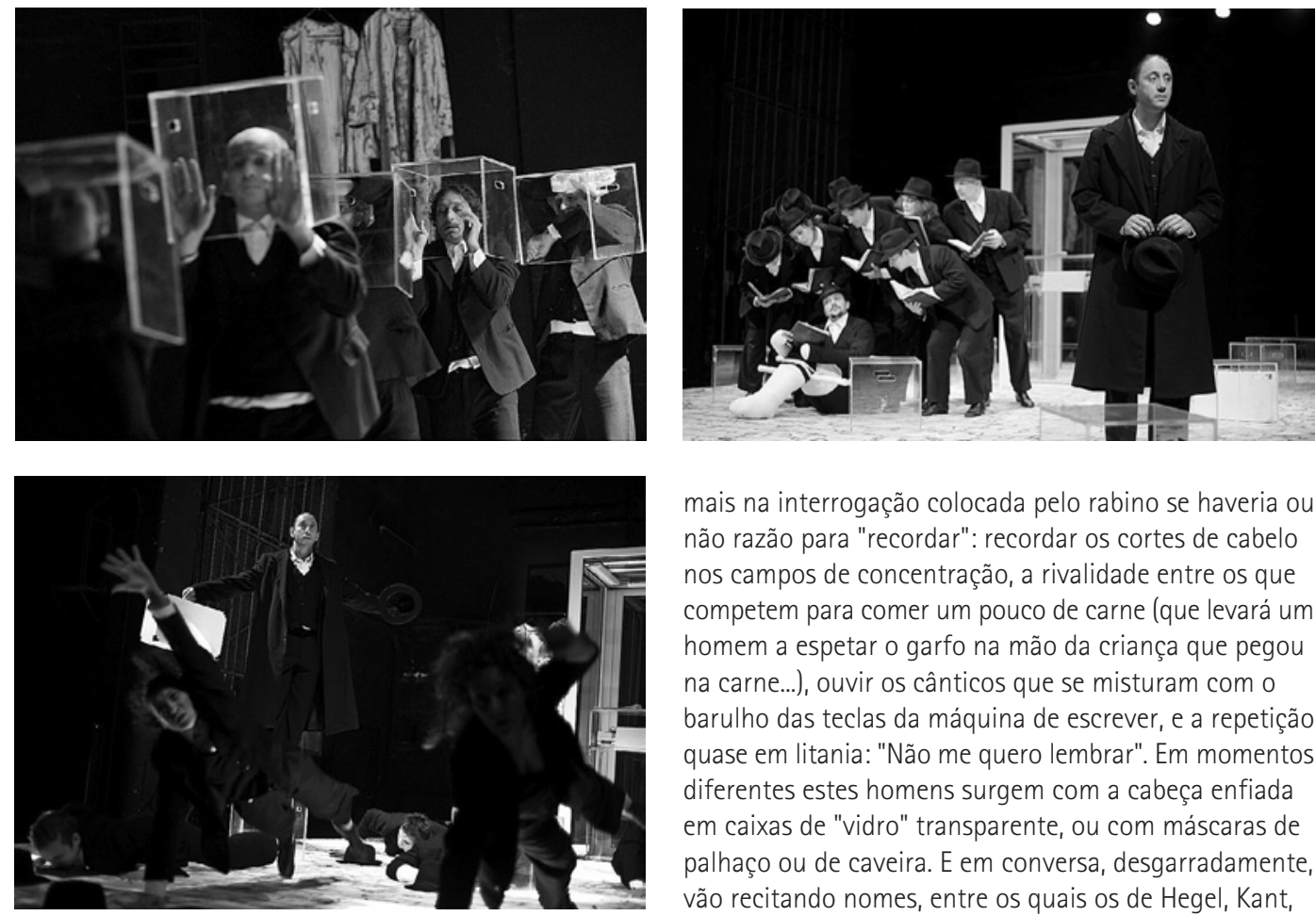

mais na interrogação colocada pelo rabino se haveria ou não razão para "recordar": recordar os cortes de cabelo nos campos de concentração, a rivalidade entre os que competem para comer um pouco de carne (que levará um homem a espetar o garfo na mão da criança que pegou na carne...), ouvir os cânticos que se misturam com o barulho das teclas da máquina de escrever, e a repetição quase em litania: "Não me quero lembrar". Em momentos diferentes estes homens surgem com a cabeça enfiada em caixas de "vidro" transparente, ou com máscaras de palhaço ou de caveira. E em conversa, desgarradamente, vão recitando nomes, entre os quais os de Hegel, Kant, Schopenhauer, Derrida, Nietzsche, não faltando, a certa altura, os acordes da canção Lili Marlene.

Uma mulher insiste em casar, mas o homem recusa personagens, como crianças marotas, para se libertarem dos constrangimentos sociais, jogam com brinquedos". A vivacidade no jogo de actores e os momentos de beleza decadente conferiam a este espectáculo um sentido de fim de festa e de tristeza instalada, ainda que o desfecho pudesse ser de resolução positiva da intriga.

Mas o espectáculo que mais fundo comoveu o público deste festival terá sido, muito provavelmente, Nascido para nunca, uma peça de András Visky que Gábor Tompa encenou de forma emotiva, acentuando necessariamente um complexo feixe de questões que colocava perante 0 público.

Reportando-se a uma realidade que recorda os campos de concentração, o espectáculo apresentava como elemento cenográfico central - e sobre um estrado quadrangular preto - uma espécie de cabine de vidro que representaria o lugar de oração dos judeus. E toda a movimentação cénica, figurinos e alguns adereços apontavam para situações referidas ao despojamento imposto e ao sentido de "expulsão", ambos reportáveis aos campos de concentração (Auschwitz em particular), mas também a uma mais genérica consideração da vida dos judeus. A questão que se erguia a partir desta representação consistia em nome de uma negação de vida a que não consegue eximir-se, tão devastadora e traumática tinha sido a vida no campo de concentração, a tremenda visão das crianças a serem levadas para os fornos crematórios. Entretanto da teia cai um saco de onde se entornam despojos reconheciveis: pratos de metal, cabeleiras, peças de roupa, sapatos, fios de prata, relógio com corrente de metal, etc. E uma pergunta obsediante: "Deus é amor, sim ou não?". À resposta negativa segue-se a pergunta agónica na escuridão "Onde estás tu?".

De uma efectiva intensidade dramática, o espectáculo invocava a dor, interrogava os limites do humano, e fazia isso na convergência de meios cénicos simples e de interpretações de grande rigor e comedimento.

Confirmando, assim, a razão do apelo que recentemente Luis Miguel Cintra invocava:

Regressemos ao teatro amador e ao teatro do colectivo. Que o teatro possa ser cada vez mais local para se tornar uma vez mais, universal. Que o teatro se torne uma vez mais o lugar inventado pela humanidade para reflectir sobre ela própria. Ou que a humanidade utilizou para ai se reflectir e se inventar a si própria. ${ }^{2}$

${ }^{2}$ Ver texto publicado na revista electrónica da Associação

Internacional de Críticos de Teatro: Critical Stages n. 5 : http://www.critical stages.org/critical stages5/entry/Whatis-Theatreabout?category=4 